\title{
EI consejo de Castilla y el control de las impresiones en el siglo XVIII. La documentación del Archivo Histórico Nacional
}

\author{
Vanesa Benito Ortega \\ Archivo Histórico Nacional* \\ vanesabenito@gmail.com
}

Recibido: 16 de diciembre de 2010

Aceptado: 23 de febrero de 2011

\begin{abstract}
Resumen
Desde el siglo XVIII el Consejo de Castilla centralizó en las dos nuevas escribanías de Gobierno el ejercicio de sus competencias sobre las impresiones con el fin de racionalizar los procedimientos, ejercer mayor control sobre la producción escrita y evitar así el fraude imperante. Los fondos documentales producidos por ambas escribanías han sido estudiados, organizados y descritos en el Archivo Histórico Nacional siguiendo una metodología de trabajo cuyos resultados se exponen en el presente artículo.
\end{abstract}

Palabras clave: Censura, Consejo de Castilla, Impresiones.

\section{The Council of Castile and the control of printed documents in Eighteenth-Century. The National Historical Archive's records}

\begin{abstract}
Since the Eighteenth Century, the Council of Castile centralised its powers on printed documents on the two new escribanias de Gobierno (Government clerk's offices) with the aim of rationalizing the administrative procedures and exerting more control on written works in order to avoid the prevailing fraud. The records produced by these clerk's offices have been studied, arranged and described by the Archivo Histórico Nacional (National Historical Archive) through a working methodology. The results thereof are explained in this article.
\end{abstract}

Key words: Censorship, Council of Castile, Printing.

Referencia normalizada

Benito Ortega V. (2011). "El consejo de Castilla y el control de las impresiones en el siglo XVIII. La documentación del Archivo Histórico Nacional". Cuadernos de Historia Moderna, Vol 36.: pp. 179-193

*Facultativa de Archivos. Años 2007-2010 


\section{Introducción}

Desde la pragmática de 7 de septiembre de 1558 el Consejo de Castilla constituyó la cabeza del sistema de censura castellano, al asumir la expedición de las licencias y privilegios de impresión y el control de la circulación de libros en romance procedentes de otros reinos y territorios de la Monarquía. La gestión de estos asuntos correspondió durante los siglos XVI y XVII a las seis escribanías de Cámara del Consejo, que tramitaron indistintamente todo tipo de expedientes gubernativos y judiciales ${ }^{1}$.

En 1627 el Consejo delegó en uno de sus ministros la concesión en la Corte de las licencias de impresión de "papeles menores" y, en el resto del territorio, en las Chancillerías y Audiencias y en los corregidores ${ }^{2}$.

En 1712 la especialización administrativa y, sobre todo, el intento de controlar el fraude de las centurias anteriores motivaron que los asuntos sobre impresiones se constituyesen como un ramo independiente del resto de negocios, a cargo de la nueva escribanía de Gobierno 3 . Por la Real Cédula de 17 de diciembre de 1716 se transplantó el modelo censor borbónico a la Corona de Aragón ${ }^{4}$, con la escribanía de Gobierno de Aragón al frente 5 . Las Audiencias aragonesas mantuvieron la facultad de corregir los impresos conforme al original y otorgar licencias de impresión de papeles sueltos. Navarra, por su parte, siempre conservó su propio régimen de excepcionalidad, mientras que los virreyes y presidentes de las Audiencias americanas se hicieron cargo de las impresiones en los territorios de Ultramar ${ }^{6}$.

La documentación generada por la escribanía de Gobierno, que responde a una novedosa concepción y práctica administrativa, ha sido identificada, clasificada y descrita en el Portal de Archivos Españoles (PARES) por el Archivo Histórico Nacional $(\mathrm{AHN})^{7}$.

${ }^{1}$ BENITO ORTEGA, Vanesa: "La imprenta y las impresiones. Aproximación a las fuentes documentales en el Archivo Histórico Nacional. Actas del Congreso Internacional Imprenta y edición musical en España (siglos XVII-XX), 3-5 de noviembre de 2010, Facultad de Formación del Profesorado y Educación, Universidad Autónoma de Madrid (en prensa).

${ }^{2}$ RUMEU DE ARMAS, Antonio: Historia de la censura gubernativa literaria en España, Madrid, Aguilar, 1940, pp. 16-19.

${ }^{3} 1712$, septiembre, 20. Auto del Consejo por que se acordó que las licencias para imprimir y reimprimir libros se pidiesen sólo por la escribanía de Cámara y Gobierno y que por las demás escribanías se pasasen a ella todos los papeles que sobre el asunto se hubiesen llevado en ellas desde veinte años antes, en ESCOLANO DE ARRIETA, Pedro: Práctica del Consejo Real, Madrid, 1796. pp. 405-488, p. 410. La planta de 10 de noviembre de 1713, situó al frente de la escribanía a un escribano de la recién extinguida Cámara. En 1717 la oficina recupera la forma anterior a 1713. AHN, Consejos, 51499, Exp. 4 bis.

${ }^{4}$ MOLL, Jaime: "Implantación de la legislación castellana del libro", en MOLL, J: De la imprenta al lector. Estudios sobre el libro español de los siglos XVI al XVIII. Madrid, Arco Libros, 1994, pp. 89-94, p. 90.

${ }^{5}$ ÁLVAREZ-COCA GONZÁLEZ, María Jesús: "La Corona de Aragón: Documentación en el Consejo y la Cámara de Castilla (1707-1834). Fuentes en el Archivo Histórico Nacional", Hispania, XLIX/173 (1989), pp. 895-948, p. 913.

${ }^{6}$ RUMEU DE ARMAS, op. cit. (nota 1), pp. 99-101.

${ }^{7}$ Portal de Archivos Españoles (PARES), http://pares.mcu.es/ [consulta: marzo de 2011]. Este trabajo se ha desarrollado en el marco del Proyecto Integral de Descripción Archivística (PIDA) de la 


\section{Punto de partida: acotamiento del objeto de estudio}

Desde que ingresaron los fondos documentales del Consejo de Castilla en el $\mathrm{AHN}^{8}$, su descripción, como la de toda la Sección, se ha realizado de forma muy desigual y siguiendo criterios archivísticos ya desfasados, de manera que, mientras de algunas series documentales existen grandes lagunas, de otras contamos con pormenorizadas descripciones 9 .

Partiendo de los trabajos de Martínez Bara, se realizaron una serie de catas entre todas las agrupaciones sobre impresiones existentes en la Sección de Consejos ${ }^{10}$, tras lo cual quedó patente que no todos los documentos que se habían asignado repetidamente al Consejo de Castilla habían sido realmente producidos por tal institución sino que muchos de ellos correspondían a las Secretarías de Estado y del Despacho, e incluso al Ministerio de la Gobernación, en el ejercicio de las competencias en materia de impresiones ${ }^{11}$.

La agrupación documental denominada en el Registro topográfico de la Sección ${ }^{12}$ Impresiones, y en concreto los legajos 5528-5574, cuentan con dos libros de matrícula que fueron elaborados por la escribanía de Gobierno para controlar los expedientes que tramitaba sobre esta materia ${ }^{13}$. Ya en el siglo XX en el Archivo Histórico Nacional se elaboraron, a partir de dichos libros, unas fichas de catálogo de autores y títulos que han servido a los investigadores durante años para bucear en estas fuentes documentales. Por esta razón, se decidió incluir en primer término dicha documentación en el proyecto descriptivo en PARES, aunque actuando siempre sobre los documentos originales.

A medida que avanzaron los trabajos, la necesidad de conocer más en profundidad el ramo de impresiones llevó a describir otras agrupaciones denominadas genéricamente Impresiones, pero esta vez de los legajos de Consejos, 50627-50678, que carecían de ningún instrumento de descripción.

De esa manera se comenzaba a tener cierto control sobre los expedientes generados por la escribanía de Gobierno. Sin embargo faltaba el estudio de unos documentos característicos del procedimiento de impresión, los impresos y manuscritos presentados al Consejo para la obtención de la licencia.

Subdirección General de los Archivos Estatales del Ministerio de Cultura, durante los años 2009-2010 y 2010-2011.

${ }^{8}$ VIGNAU Y BALLESTER, Vicente: Memoria del Archivo Histórico Nacional (1896-1899), Madrid, 1899.

${ }^{9}$ ARCHIVO HISTÓRICO NACIONAL. SECCIÓN DE CONSEJOS. BERNAL ALONSO, Eva y MIGUEL, Juan Carlos de: Informe sobre el estado descriptivo de la Sección de Consejos en el Archivo Histórico Nacional. 2010.

${ }^{10}$ MARTÍNEZ BARA, José Antonio: "Fuentes para el estudio de la Imprenta en el Archivo Histórico Nacional". Conferencia pronunciada en la Fundación Universitaria Española el 6 de mayo de 1977, Cuadernos para la investigación de la literatura hispánica, 9 (1988), pp. 207-226.

${ }^{11}$ Los resultados de dicha identificación en BENITO ORTEGA, op. cit. (nota 1).

${ }^{12}$ ARCHIVO HISTÓRICO NACIONAL. SECCIÓN DE CONSEJOS. Registro de legajos de la Sección de Consejos, 1-53229, Madrid, s. f. El instrumento es el nº 21-6.

${ }^{13} \mathrm{AHN}$, Consejos, L, 2713 y 2714. 
Así, se decidió incluir la descripción de los Originales de Imprenta (Consejos, 5770-5797), de los que únicamente disponíamos de unas fichas de catálogo con signatura topográfica antigua y que, en consecuencia, eran muy poco accesibles para los investigadores. El resto de originales, incluidos en la agrupación de Impresos y Manuscritos contaban con el catálogo impreso de Natividad Moreno Garbayo, por lo que de momento quedaron excluidos ${ }^{14}$.

El proyecto de descripción que se presenta ha abarcado en definitiva la documentación generada por la escribanía de Gobierno a lo largo de todo el proceso administrativo de gestión de las impresiones $\mathrm{y}$, en concreto, se han descrito los documentos que estaban organizados en el Registro topográfico de la Sección, en las agrupaciones denominadas Impresiones (Consejos 5528-5574 y parte de 5062750678), y Originales de Imprenta (Consejos, 5770-5797).

\section{Estudio del "ramo de imprentas"15}

\subsection{Organismos competentes sobre las impresiones durante los siglos XVIII y XIX}

Si desde 1558 las escribanías del Consejo de Castilla, primero las de Cámara y después las de Gobierno, se encargaron de la expedición de las licencias y privilegios de impresión y de los libros que se pretendían introducir en el reino, los conflictos surgidos entre libreros, impresores y autores, y el control de las infracciones en materia de impresiones correspondieron desde el siglo XVII al Juzgado o Comisión de Imprentas.

Los orígenes de tal oficina arrancan en el consejero comisionado por el tribunal castellano en 1627 para otorgar licencias de los papeles menores. Aunque se desconoce la fecha exacta de su creación como tal juzgado, existen noticias de que en 1718 estaba plenamente constituido ${ }^{16}$, hasta el punto de que el juez de Imprentas, sin dejar de lado los asuntos contenciosos, acabó desempeñando todas las tareas en materia de censura, expidiendo incluso licencias de impresión y de publicación de obras. Durante esta etapa el Consejo actuó de manera simbólica y la escribanía de Gobierno se encargó meramente de las certificaciones de las licencias ${ }^{17}$. El sistema quedaba cerrado con la actuación de los subdelegados de Imprentas en todo el territorio, que sustituyeron a las Audiencias y corregidores.

${ }^{14}$ ARCHIVO HISTÓRICO NACIONAL. SECCIÓN DE CONSEJOS. MORENO GARBAYO, Natividad: Catálogo de impresos y manuscritos. Años 1520-1877, legs. 50696-50841, Madrid, 1998. Parte de esta documentación está además descrita en el Catálogo Colectivo del Patrimonio Bibliográfico. Ministerio de Cultura. http://www.mcu.es/patrimoniobibliografico/cargarFiltroPatrimonioBibliografico.do? cache=init\&layout $=$ catBibliografico\&language $=$ es [consultado en marzo de 2011].

${ }^{15}$ Sobre el "ramo de imprentas" en el siglo XVIII, véase el trabajo de los tratadistas y escribanos de Gobierno MARTÍNEZ SALAZAR, Antonio: Colección de memorias y noticias del gobierno general $y$ político del Consejo, Madrid, 1764 y ESCOLANO DE ARRIETA, Pedro, op. cit. (nota 3).

${ }^{16}$ RUMEU DE ARMAS, op.cit. (nota 1), p. 29.

${ }^{17}$ Los expedientes en los que el juez de imprentas maneja todo el trámite administrativo, sobre todo durante la época de Juan Curiel (1752-1769), se pueden localizar en la [antigua] agrupación de Impresiones, AHN, Consejos, 50627-50678 y han sido parcialmente descritas en el PIDA 2009-2010. 
Las numerosas irregularidades generadas con motivo de la independencia del Juzgado respecto del Consejo supusieron que, tras la etapa en que ejerció el cargo de juez Juan Curiel (1752-1769), la Sala Primera de Gobierno, a través de su escribanía, volviese a despachar las censuras y licencias de impresión. Desde entonces el Juzgado de Imprentas volvió a asumir funciones meramente contenciosas y a aprobar las licencias de impresión de papeles menores ${ }^{18}$. Sólo en 1785 cuando asumió la censura de papeles periódicos adquiriría de nuevo cierta relevancia. Las reformas en el territorio supusieron la supresión de los subdelegados de Imprentas y la vuelta de las competencias sobre impresiones a manos de los regentes de las Chancillerías, de los presidentes de las Audiencias y de los corregidores.

El periodo de 1769 a 1805 se caracterizó por un férreo control de la producción impresa por parte del Consejo que, auxiliado por el Juzgado de Imprentas y el fiscal, actuó de oficio en numerosas ocasiones contra libreros e impresores que habían publicado sin licencia, revisó el contenido de obras ya impresas con permiso y controló la frontera para evitar la introducción de escritos y libros desde otros reinos, fundamentalmente desde Francia.

Sin embargo, este fuerte control se ejerció de manera paralela por parte del propio monarca, que comenzó a encargarse personalmente de la impresión de libros y papeles a través de sus Secretarías de Estado y del Despacho. De hecho desde 1744 la Primera Secretaría de Estado concedía los permisos para la publicación de obras que afectaban a materias de su competencia y acabó encargándose de la gestión de la Imprenta Real y de la Guía de Forasteros. A fines del siglo XVIII y principios del XIX aparecen también concediendo licencias las Secretarías de Estado y del Despacho de Gracia y Justicia y la de Hacienda ${ }^{19}$.

El final del reinado de Carlos IV supuso un duro golpe para el Consejo de Castilla. El Reglamento de 1805 reconoció a un nuevo juez de Imprentas y Librerías del Reino, dependiente de la Secretaría de Estado y del Despacho de Gracia y Justicia y con competencias exclusivas sobre el "ramo de impresiones". Se privaba así al Consejo de unas atribuciones centenarias, que no recuperaría hasta 1808.

La Guerra de la Independencia y los sucesos políticos posteriores determinaron el inicio del fin del sistema de censura del Antiguo Régimen en España. La libertad de imprenta, uno de los anhelos de los liberales de Cádiz, quedó consagrada en el decreto de las Cortes de 10 de noviembre de 1810, por el que se suprimieron los juzgados de Imprentas y la censura previa, salvo para los escritos religiosos, que debían pasar la aprobación de los ordinarios eclesiásticos. Los delitos de imprenta pasaron a ser competencia de los jueces y tribunales ordinarios y se creó una Junta Suprema de Censura para asegurar la libertad de impresión y contener los abusos.

${ }^{18}$ GONZÁLEZ PALENCIA, Ángel: "Joaquín Ibarra y el Juzgado de Imprentas", Revista de la Biblioteca, Archivo y Museo del Ayuntamiento de Madrid, 13, 49 (1944), pp. 5-47 y GONZÁLEZ PALENCIA, Ángel: El sevillano don Juan Curiel, juez de Imprentas, Sevilla, 1945.

${ }^{19}$ La documentación de las Secretarías de Estado se localiza en la [antigua] agrupación de Imprentas y Agregados (Consejos, 11275-11311). Sobre la producción documental de estas instituciones en relación con el control de las licencias de impresión véase BENITO ORTEGA, op.cit., (nota 2). 
La dialéctica entre el régimen liberal y el orden tradicional repercutió lógicamente en el sistema de control de las publicaciones vigente en cada momento, de forma que, frente a periodos de censura previa, existieron otros en que rigió la libertad de imprenta. En el año 1834 se dio carpetazo definitivamente al sistema antiguo de licencias con la supresión del Consejo de Castilla y del Juzgado de Imprentas y Librerías del Reino.

\subsection{EIConsejo de Castilla. Forma de trabajo y archivo de la escribanía de Gobierno}

A pesar de que la escribanía de Gobierno venía funcionando plenamente desde 1717, no queda constancia documental de la separación del "ramo de imprentas" del resto de asuntos gubernativos hasta que Miguel Fernández Munilla asume el control de la misma en 1728. Las series finalizan en 1834 con la liquidación definitiva del Consejo, existiendo como es lógico las lagunas propias de los periodos en los que fue suprimido.

Hasta mediados del Setecientos se mantuvieron las antiguas prácticas de archivo de expedientes consistentes en mantener separados los tipos documentales surgidos de las diferentes partes del trámite para la impresión y venta de escritos, con lo cual las licencias y privilegios de impresión y reimpresión y sus tasaciones carecían de vinculación alguna.

En torno a 1750 comenzaron a unirse las dos partes del procedimiento en un mismo expediente que quedaba asentado para su control en unos libros de matrícula y era archivado en su año de formación ${ }^{20}$. Cuando se generaban más licencias, privilegios, recursos o pleitos tocantes a la misma obra, autor, solicitante u otro nexo común, se añadían al primero, creándose así una especie de expediente general pero éstos ya no se matriculaban. Los criterios de la escribanía para formar los expedientes eran muy diversos. La mayor parte de las veces se cosían los relativos a la misma obra, solicitados o no por la misma persona. Sin embargo, en ocasiones éstos se archivaban por separado, uniéndose por ejemplo varios tomos de una obra por un lado y el resto por otro, contando en consecuencia con asientos diferentes en el libro de matrícula. En definitiva, las descripciones de los libros de matricula y de las fichas de catálogo elaboradas sobre dichas matrículas perdían valiosa información al no incluir los diferentes privilegios, licencias, tasaciones, pleitos, etc. de un expediente, cuya descripción se ha acometido ya en este proyecto.

A pesar de esta aparente disparidad, el trabajo de la escribanía era muy regular. Todas las certificaciones de licencias y privilegios de impresión y reimpresión concedidos se asentaban sistemáticamente en unos registros, de los que se ha conservado una muestra entre 1766 y $1805^{21}$.

Resulta muy habitual encontrar en los expedientes obras manuscritas o impresas con anotaciones de la censura o rúbricas del escribano, pero lo común es que este material se archivase separadamente por la escribanía de Gobierno como era

\footnotetext{
${ }^{20}$ AHN, Consejos, L. 2713 y 2714 (1728-1734).

${ }^{21}$ AHN, Consejos, L.2716.
} 
costumbre desde el siglo XVI. Los ejemplares que se guardaban cada año eran asentados en otros libros de control ${ }^{22}$.

\section{Identificación y descripción de las series documentales}

El proyecto descriptivo ha permitido un conocimiento profundo del sistema censor vigente en Castilla y en los territorios aragoneses desde el siglo XVIII hasta la supresión del Consejo en 1834, y la consiguiente organización de la documentación dentro del cuadro de clasificación de fondos del Archivo, accesible a través de PARES / Inventario Dinámico ${ }^{23}$. Dicha organización ha sido el resultado de la aplicación de una metodología de trabajo que detallaremos a continuación, desarrollada no sin poca dificultad debido al escaso conocimiento previo de las instituciones productoras, de su formadetrabajoytramitaciónadministrativa.Comoeslógicohaidosufriendomodificaciones a lo largo del proyecto y aún es susceptible de algunos cambios, sobre todo cuando se acometa la descripción de otras oficinas como el Juzgado de Imprentas.

La concepción que en el siglo XVIII se tenía del "ramo de imprentas" como un ramo aparte e independiente del resto de asuntos sustanciados en Sala de Gobierno y la transposición de esta idea a las prácticas administrativas de la escribanía de Gobierno, requería un tratamiento documental que fuera fiel reflejo de ello. Resultaba necesario organizar las series documentales que se identificasen en torno a las competencias del Consejo de Castilla sobre las impresiones, para evitar así mezclarlas con otros asuntos tramitados por la escribanía. Así en el cuadro de clasificación de fondos del AHN se creó una división de fondo, por debajo de la escribanía de Gobierno, denominada Imprenta e impresiones, y de la que colgarían las series identificadas a lo largo del proceso descriptivo.

\section{INSTITUCIONES DEL ANTIGUO RÉGIMEN \\ 1.1. INSTITUCIONES DE LA MONARQUÍA \\ (F) CONSEJO DE CASTILLA ${ }^{24}$}

(1D) ESCRIBANÍA DE GOBIERNO. CONSEJO DE CASTILLA (2D) IMPRENTAS E IMPRESIONES

(S) Embargo de ediciones y recogida de ejemplares impresos.

(S) Impresos y originales de imprenta.

(S) Introducción y venta de obras impresas desde el extranjero.

\footnotetext{
${ }^{22}$ Inventario de los libros y papeles que fueron enlegajados entre 1728 y 1805 por la Escribanía de Gobierno. AHN, Consejos, L. 2715.

${ }^{23} \mathrm{http} / / /$ pares.mcu.es/ParesBusquedas/servlets/Control_servlet [consultado en abril de 2011].

${ }^{24} \mathrm{~F}$ : fondo; 1D: primera división de fondo; 2D: segunda división de fondo; 3D: tercera división de fondo; S: serie.
} 
(S) Legislación y reglamentación de imprentas e impresiones.

(S) Libros de matrícula de impresiones.

(S) Libros registro de certificaciones de licencias y privilegios de impresión y reimpresión.

(S) Licencias y privilegios de impresión y reimpresión.

(S) Nombramientos de jueces y subdelegados de Imprentas e impresores del Consejo.

(S) Pleitos sobre impresiones.

(S) Tasaciones y licencias de publicación y venta de obras y papeles impresos.

(1D) ESCRIBANÍA DE CÁMARA Y DE GOBIERNO DE ARAGÓN. ESCOLANO DE ARRIETA. CONSEJO DE CASTILLA (2D) ESCRIBANÍA DE GOBIERNO DE ESCOLANO DE ARRIETA. CONSEJO DE CASTILLA

(3D) Imprentas e impresiones ${ }^{25}$

(S) Impresos y originales de imprenta.

(S) Licencias y privilegios de impresión y reimpresión.

\section{A) Series documentales de la escribanía de Gobierno de Castilla}

\section{A.1. Licencias y privilegios de impresión y reimpresión}

En los primeros años del siglo XVIII el procedimiento para imprimir comenzaba con la solicitud y presentación de la obra ante el Consejo de Castilla. El escribano, en nombre de la Sala de Gobierno, sometía la instancia a la firma del gobernador del Consejo y la remitía al juez de Imprentas o "al señor de la encomienda", quien mandaba la obra a la censura. Tras los informes pertinentes la Sala de Gobierno otorgaba o denegaba la licencia. En el primer caso, la obra se enviaba de nuevo al escribano para que rubricase el original en todas sus planas y salvase las enmiendas y tachaduras, tras lo cual expedía la certificación de la licencia, que quedaba asentada en los librosregistro, creados al efecto ${ }^{26}$. Si la licencia era rechazada el original se archivaba en el Consejo, mientras que si el texto era finalmente impreso retornaba a la escribanía con el manuscrito original para ser cotejado y enmendado por el corrector general. A

\footnotetext{
${ }^{25}$ Esta documentación apareció mezclada con la de la escribanía castellana, por lo que se describió y clasificó.

${ }^{26} \mathrm{AHN}$, Consejos, L.2716.
} 
continuación se fijaba el precio y se expedía la certificación de la tasa, tras lo cual se podía proceder a su publicación y venta. En las reimpresiones, en vez del original, había que presentar el libro que se pretendiese imprimir y si no tenía enmiendas ni adiciones se ahorraba el trámite de la censura. Por su parte los privilegios permitían a los autores disfrutar de un monopolio de impresión durante un número determinado de años.

Desde 1712 el procedimiento quedó desvirtuado al asumir el portero de la Comisión de Imprentas el despacho de los expedientes y, el juez, la concesión de todo tipo de permisos de impresión y publicación como delegado del Consejo. Hacia 1752 este ministro aparece actuando a título individual, limitándose la escribanía de Gobierno a expedir las certificaciones ${ }^{27}$.

Cuando en 1762 fue abolida la tasa de libros, los autores debían acudir igualmente a él a fin de obtener el permiso de publicación y venta. Sin embargo esta última traba para la impresión se suprimió por real orden de 30 de mayo de 1763, lo que significaba que la certificación de licencia bastaba para la impresión, publicación y venta de la obra. Ese mismo año se introdujeron otras reformas en el sistema debido a las continuas quejas de impresores y libreros. Con la supresión del cargo de portero de la Comisión de Imprentas, la escribanía de Gobierno asumiría de nuevo la tramitación de las licencias y el juez de Imprentas volvería a ser un mero comisionado del Consejo.

Los expedientes que se conservan entre la documentación de la escribanía de Gobierno responden perfectamente al trámite anterior, muy normalizado y reglado. Las modificaciones que hemos descrito resultan absolutamente lógicas dentro de la dinámica de lucha por el poder interno en el Consejo de Castilla y debido al amplio ámbito cronológico de vigencia del procedimiento para la impresión de libros.

La serie documental de Licencias y privilegios de impresión y reimpresión constituye sin duda la principal y más voluminosa de las tramitadas por la escribanía de Gobierno sobre impresiones ${ }^{28}$. Arranca en 1728 -salvo algunos documentos aislados que llegan a 1682- y finaliza en 1834. Bajo esta denominación hemos aglutinado diversos tipos documentales que responden a las modificaciones en el trámite para la publicación de libros durante los siglos XVIII y XIX.

Desde el año 1728 hasta mediados del siglo XVIII se han incluido las licencias de impresión, las reimpresiones y los privilegios. Estos tres tipos de expedientes constituyen la primera parte del procedimiento de edición, formados por la instancia, el informe de la censura y la denegación o concesión de la licencia o privilegio de impresión y reimpresión, es decir, no contienen la tasa y por lo tanto no implican el permiso de publicación y venta de las obras. Se trata de expedientes muy sencillos y normalizados, en tamaño cuarto, que no suelen sobrepasar los dos folios, empleándose la misma hoja de la instancia para el informe del censor y la certificación del permiso ${ }^{29}$.

${ }^{27}$ RUMEU DE ARMAS, A: op. cit. (nota 1), pp. 30-31. La documentación sobre esta etapa en la [antigua] agrupación de legajos de Impresiones, (Consejos, 50.627-50678).

${ }^{28}$ Todos los expedientes descritos hasta la fecha proceden de la agrupación documental de Impresiones (Consejos, 5528-5574 y 50.627-50678).

${ }^{29}$ Estos expedientes se localizan en la [antigua] agrupación de los legajos de Impresiones, (Consejos, 50627-50678). 
Desde mediados del siglo XVIII hasta 1762 predominan los expedientes en los que ya se han unido las dos partes del procedimiento de licencia y tasa, y ya pueden incorporar ejemplares impresos y originales de impresión cosidos o adjuntos.

Por último, entre 1762 -fecha de la abolición de la tasa- hasta 1834, los expedientes producidos por la escribanía ya implican permiso, no sólo para imprimir, sino también para la publicar y vender la obra. Quizá estos son los expedientes más complejos al coincidir con la etapa de fortalecimiento del Consejo de Castilla. Abundan pues los expedientes de carácter general que incluyen varias licencias y privilegios, pleitos, embargos de ejemplares, etc.

A este tipo de documentos les hemos asignado un título general, normalmente "licencias y privilegios de impresión y reimpresión de la obra...", y se han descrito las distintas partes que los integran en el campo de "Alcance y contenido" de la ficha descriptiva. De igual modo se ha procedido con los expedientes en los que se solicita licencia de impresión para varias obras si la lista fuese muy extensa. Así se ha conseguido no perder información, tal y como sucedía con la descripción aportada por los libros de matrícula y las fichas de catálogo.

En cuanto a la elección del título de las obras, hemos optado siempre por el normalizado según el Catálogo de la Biblioteca Nacional ${ }^{30}$ o por el título más completo que apareciera en los documentos, si la obra no estuviese catalogada.

\section{A.2. Tasaciones y licencias de publicación y venta de obras y papeles impresos ${ }^{31}$}

La serie, que se inicia en 1728 , está constituida fundamentalmente por las solicitudes de tasaciones de libros ya impresos con la preceptiva licencia. Es por lo tanto producto delasegundapartedel procedimientodeedición,queimplicabaelpermisodepublicación y venta de la obra. Junto a estos expedientes, muy sencillos, en tamaño cuarto y que normalmentenosuperanlos dosfolios, sehanincluidolosescasos expedientesgenerados sobre publicación y venta de escritos posteriores a 1762 .

El 14 de noviembre de 1762 Carlos II mandó abolir la tasa de libros, a excepción de la de algunos que, por considerarse necesarios para el bien común, debían tener un precio controlado por el Estado. Los autores, sin embargo, seguían obligados a obtener el permiso de publicación y venta de sus obras, traba que se suprimiría un año después por la real orden de 30 de mayo de 1763. Desde entonces, con la certificación de la licencia bastó para la impresión, publicación y venta de los escritos. La disposición fijó asimismo qué textos quedarían sujetos a la tasa: "Catón Cristiano", "Vía Crucis" y los demás de este tipo; las cartillas de Valladolid; los catecismos del padre Ateste y Ripalda; y las cartillas escolares de los niños ${ }^{32}$.

${ }^{30} \mathrm{http}: / /$ catalogo.bne.es/uhtbin/webcat [consulta: marzo de 2011].

${ }^{31}$ La serie se localizan en la [antigua] agrupación de los legajos de Impresiones (Consejos, 55285574 y $50.627-50678)$.

${ }^{32}$ GARCÍA CUADRADO, Amparo: "Aproximación a los criterios legales en materia de imprenta durante la Edad Moderna en España”, Revista General de Información y Documentación. VI, 2 (1996), pp. 125-187, p. 181-182. 


\section{A.3. Impresos y originales de imprenta ${ }^{33}$}

Bajo esta denominación hemos incluido los originales de imprenta presentados al Consejo para la obtención de la licencia o privilegio que, como ya hemos visto, se archivaban separados de sus expedientes. Muchas veces llevan anotada la concesión de licencia o conservan entre sus páginas el expediente de solicitud. Su rasgo más característico son las rúbricas del escribano de Gobierno en todas sus planas, además de diferentes enmiendas y tachaduras a lo largo del texto ${ }^{34}$. En el caso de las solicitudes para reimprimir una obra se presentaba el ejemplar impreso con los añadidos y correcciones que se pretendían introducir en la nueva edición.

Casi todos los documentos descritos en el proyecto son originales de Imprenta, pero junto a ellos, la serie documental está compuesta por los impresos entregados al Consejo en cumplimiento de la legislación.

Desde el siglo XVI, cuando se fijó el sistema de censura gubernativa ${ }^{35}$, los editores adquirieron una serie de obligaciones tras la impresión de la obra. Uno de estos deberes marcó el formato del libro hasta la actualidad. Así, en la portada debía constar la licencia, la tasa, el privilegio, el nombre del autor e impresor, el lugar y el año de impresión.

La otra obligación ha sido vista por muchos autores como el origen del Depósito Legal. Los editores debían entregar un ejemplar de la obra impresa al gobernador del Consejo, a cada uno de sus ministros y a otras instituciones que marcaban las leyes. Lo gravoso de esta práctica hizo que en 1711 se redujese el número de ejemplares, aunque se mantuvo en todas las normas la obligatoriedad de hacer llegar uno a la recién creada Real Biblioteca, a la de El Escorial y al gobernador del Consejo, respectivamente.

Intuimos que muchos de los ejemplares entregados al Consejo acabaron mezclándose con los originales de imprenta, a los que se añadieron para mayor confusión todo tipo de impresos con posterioridad, formándose así una colección. La identificación del material que no es original de imprenta resulta muy dificultosa ya que no suele incorporar ninguna anotación que indique su procedencia ${ }^{36}$.

\footnotetext{
${ }^{33}$ Estos ejemplares proceden de la [antigua] agrupación de Originales de Imprenta (Consejos, 5770-5797), descrita en su totalidad, y de la de Impresiones (Consejos, 5528-5574), donde han aparecido algunos volúmenes sueltos sin vinculación con ningún expediente. Con el tiempo se incluirán aquí los que correspondan de la agrupación de Impresos y Manuscritos (Consejos, 50696-50842) y los ejemplares con signatura Consejos, 51623-51628, de Imprenta e Impresiones.

${ }^{34}$ Resultan muy interesantes para el estudio de este tipo documental los artículos de ANDRÉS ESCAPA, Pablo (y otros): "El original de imprenta", pp. 29-64; GARZA MERINO, Sonia: "La cuenta del original", pp. 65-95 y DADSON, Trevor J.: "La corrección de pruebas", pp. 97-128, RICO, Francisco (dir.): Imprenta y critica textual en el Siglo de Oro, Valladolid, Universidad de Valladolid, 2000.

${ }^{35}$ GONZALEZ PALENCIA, Ángel: Estudio histórico sobre la censura gubernativa en España (1800-1833), Madrid, Tipografía de Archivos, 1934-1941.

${ }^{36} \mathrm{La}$ fecha final de la agrupación de Originales de Imprenta descrita en PARES es 1846, cuando el Consejo llevaba doce años suprimido. Ello demuestra que las prácticas de archivo se mantuvieron más allá de la pervivencia de la propia institución. Por su parte los ejemplares de la [antigua] agrupación de Impresos y Manuscritos, que llegan hasta 1877, están más mezclados y resultará más dificultosa su descripción e identificación.
} 
Además desde el punto de vista de la descripción de estos documentos se han hecho frente a otros retos. El hecho de que los originales de imprenta formen parte de un procedimiento administrativo, que incluyan correcciones y rúbricas y que en ocasiones lleven anotada la certificación de la licencia, otorga a estos ejemplares el carácter de expedientes y, en definitiva, de documentos de archivo ${ }^{37}$. Por esta consideración las normas bibliotecarias no nos eran de utilidad a la hora de acometer la descripción de los mismos, así que hubo que establecer una serie de criterios descriptivos, inexistentes en el campo de la archivística hasta el momento. Entre algunas cuestiones se acordó diferenciar entre las unidades documentales simples, con una fecha de creación expresada por el año, de las unidades documentales compuestas, en las que se consignarían las fechas extremas, teniendo en cuenta las del texto y las de la censura o licencias que incorporase. Además se acordó indicar si se trataba de un libro (más de 50 páginas) o de un folleto (menos de 50 ), de un ejemplar impreso o manuscrito, y expresar las medidas y el número de páginas (los impresos) o de folios (los manuscritos).

\section{A.4. Embargo de ediciones y recogida de ejemplares impresos y Pleitos sobre impresiones $^{38}$}

Estas dos series documentales son producto de las actuaciones contenciosas y judiciales del Consejo de Castilla en la gestión de las impresiones. La mayoría de los expedientes se inicia en la década de 1760, coincidiendo de nuevo con el periodo de fortalecimiento del Consejo, con el conde de Aranda como Presidente y Pedro Rodríguez Campomanes de fiscal.

Bajo la denominación de Embargo de ediciones y recogida de ejemplares impresos, hemos integrado los expedientes generados en la escribanía de Gobierno con motivo de las pesquisas realizadas contra quienes habían impreso sin el preceptivo permiso del Consejo o habían contravenido las leyes en materia de impresión. Las penas por este tipo de delitos implicaban la cárcel y el embargo de las obras, por lo que en numerosas ocasiones, los expedientes incluyen los ejemplares incautados. Normalmente el trámite se iniciaba de oficio, a instancia del fiscal, del juez de Imprentas o de otra institución, pero también se incoaban como resultado de una denuncia.

Los pleitos, por su parte, están constituidos por los conflictos entre particulares en la pugna por derechos de impresión y por lo tanto contienen las diferentes licencias y privilegios otorgados o denegados a los litigantes. Además, como característica propia de la serie, los expedientes pueden incorporar los contratos suscritos entre los autores, impresores, mercaderes, etc. ${ }^{39}$.

Ya vimos cómo, antes de que la escribanía de Gobierno asumiese la tramitación de estos asuntos, se encargó de ellos la Comisión de Impresiones o Juzgado de

\footnotetext{
${ }^{37}$ Sobre los impresos y originales de imprenta del AHN véase BENITO ORTEGA, op.cit., (nota 2).

${ }^{38} \mathrm{La}$ serie se ha identificado entre la documentación de Impresiones (Consejos, 5528-5574).

${ }^{39}$ PÉREZ PASTOR, Cristóbal: "Escrituras de concierto para imprimir libros", Revista de Archivos, Bibliotecas y Museos. I, 8-9(1987), pp. 363-371.
} 
Imprentas ${ }^{40}$, por lo que la descripción de la documentación de esta oficina revelará nuevos datos sobre esta importante función del Consejo de Castilla.

\section{A.5. Introducción y venta de obras impresas desde el extranjero ${ }^{41}$}

La serie documental se inicia en 1759 , aunque la mayoría de los expedientes datan de mediados de los ochenta del siglo XVIII. Bajo esta denominación hemos incluido las unidades documentales generadas por la escribanía de Gobierno en el control de la introducción de libros procedentes del exterior.

Si la pragmática de 7 de septiembre de 1558 reguló la introducción en Castilla de libros en romance desde Aragón, Valencia, Cataluña y Navarra, la frontera en el siglo XVIII se estableció en los límites con Portugal y en los Pirineos. Con el avance de las ideas enciclopédicas se endurecieron las medidas contra los libros impresos en el exterior, imponiéndose restricciones a la circulación de impresos entre los distintos reinos peninsulares.

La real cédula de 17 de marzo de 1778 insistió en la necesidad de fiscalizar los escritos en la frontera. Este sistema de control obligaba a que los libros se retuvieran en los organismos aduaneros hasta que el Consejo otorgase la pertinente licencia para introducirlos y comercializarlos en España. Al juez de Imprentas le correspondía velar por su estricto cumplimiento.

Conforme avanzó la Revolución Francesa se habilitaron otros mecanismos disuasorios, caso de la prohibición de que penetrasen sin licencia de la Secretaría de Estado textos escritos en lengua de aquel país o relativos a su constitución o situación socio-política. Por la real orden de 15 de octubre de 1792 se eximía al Consejo de la censura de libros producidos fuera de España, competencia que sería asumida por los revisores de aduanas y que el tribunal castellano no recuperaría hasta 1802.

La regulación sobre introducción de libros correrá paralela a la general en materia de impresiones de manera que, en el reglamento de 1805, el control de la frontera quedó encomendado a un juez de Imprentas y Librerías del Reino, dependiente de la Secretaría de Estado y del Despacho de Gracia y Justicia. En 1808 el Consejo de Castilla recuperó de nuevo el control de las impresiones y, desde entonces, salvo los periodos liberales en los que se impuso la libertad de imprenta, no habrá novedades hasta las reales cédulas de 1824 y 1825 por las que se reiteraron y fijaron las reglas que debían observarse para la introducción de libros y papeles desde el extranjero ${ }^{42}$.

En último lugar hemos identificado varias series propias de la gestión diaria de la escribanía:

${ }^{40}$ Los legajos de Consejos, 51629-51634 de la [antigua] agrupación Imprenta e impresiones, contienen pleitos entre particulares producidos por el Juzgado de Imprentas (1731-1769). Además hay documentación entre 1720-1835 en la agrupación de Juzgado y Comisión de Imprentas (Consejos, 50683-50695) y en algunos legajos de la Inspección de Imprentas (Consejos, 11343-11351) para los años $1820-1834$.

${ }^{41}$ La serie documental se ha identificado entre la [antigua] agrupación de Impresiones (Consejos, 5528-5574 y 50.627-50678) y Originales de imprenta (Consejos, 5770-5797).

${ }^{42}$ RUMEAU DE ARMAS, op. cit. (nota 1), pp. 65-88 y 175-188. 


\section{A.6. Legislación y reglamentación de imprentas e impresiones ${ }^{43}$}

La serie documental arranca en 1680, es decir, con anterioridad a la creación de la escribanía de Gobierno, por lo que suponemos que los documentos fueron reunidos por dicha escribanía para la gestión cotidiana de los asuntos que tramitaba. Son originales de reales cédulas, decretos, órdenes y otro tipo de disposiciones relativas a la impresión de libros y papeles en los reinos de la Monarquía.

\section{A.7. Libros de matrícula de impresiones y Libros registro de certificaciones de} licencias y privilegios de impresión y reimpresión

La primera serie está integrada por los dos libros de matrícula de expedientes de la escribanía y el registro de los libros enlegajados cada año entre 1728 y $1734^{44}$. La segunda por el registro donde, como hemos visto, se asentaban las certificaciones de licencias de impresión ${ }^{45}$.

\section{A.8. Nombramientos dejueces y subdelegados deImprentas e impresores del Consejo ${ }^{46}$}

De esta serie se han identificado únicamente seis unidades documentales entre 1718 y 1790.

\section{B. Series documentales de la Escribanía de Gobierno de Aragón}

Cuando se realizaba la descripción de los legajos de la escribanía de Gobierno se localizaron algunos expedientes correspondientes a la de Aragón sin asentar en los libros de matrícula ${ }^{47}$.

La explicación de esta mezcla de documentos de las dos escribanías puede deberse a que, en numerosas ocasiones, cuando se ausentaba algún escribano de Gobierno, el de la otra escribanía pasaba a sustituirle interinamente, y aunque se llevaba con rigurosa pulcritud la forma de archivo, puede que los expedientes llegaran a mezclarse ${ }^{48}$.

Aunque no se ha realizado un estudio profundo de la documentación de esta escribanía, ya que no era objeto del Proyecto de Descripción Archivística, podemos afirmar que las series documentales producidas por ésta son exactamente las mismas que las de la escribanía de Gobierno ya que el trámite para la impresión imperante en Castilla se trasladó completamente a partir de la real cédula de 17 de diciembre de 1716 , de lo cual ha quedado buena prueba documental.

\footnotetext{
${ }^{43}$ Identificada entre la [antigua] agrupación de Impresiones (Consejos, 5528-5574 y 50627-50678).

${ }^{44}$ Consejos, L. 2713, 2714 y 2715.

${ }^{45}$ Consejos, L. 2716 (1766-1805).

${ }^{46}$ Serie identificada de Impresiones (Consejos, 5528-5574 y 50627-50678).

${ }^{47}$ Impresiones (Consejos, 5528-5574).

${ }^{48}$ ESCOLANO DE ARRIETA y MARTÍNEZ SALAZAR, op. cit. (nota 21).
} 
Las únicas concesiones que se hicieron a los impresores aragoneses fueron el nombramiento en cada reino de un corrector para cotejar el manuscrito original con el impreso, la aprobación de las licencias de impresión de "papeles menores" por parte de las Audiencias y, por último, la elaboración de informes de los gobernadores sobre el número de pliegos y precio de las obras, lo que se impuso como requisito previo a la solicitud de la tasa al Consejo de Castilla ${ }^{49}$. En todo lo demás los procedimientos fueron similares.

Como resultado de la descripción de esta documentación se incluyeron las series documentales identificadas en el cuadro de clasificación, dentro de la escribanía de Gobierno de Aragón y, en concreto, por debajo de la división de fondo de Imprentas e Impresiones. Es decir, se reproducela estructura del cuadrode la escribanía de Gobierno castellana. Se trata, en concreto, de treinta unidades documentales correspondientes a las series de Impresos y Originales de imprenta y de la de Licencias y privilegios de impresión y reimpresión. Cuando se describa el resto de la documentación de la escribanía, saldrán sin duda más series documentales. El problema fundamental será la localización de esta documentación ya que hay muy poca identificada, por lo que intuimos que habrá más expedientes aragoneses mezclados entre los de la escribanía de Gobierno castellana. A este respecto resulta interesante el acuerdo adoptado por el Consejo en 1779 para que pasaran a la escribanía de Gobierno de Antonio Martínez Salazar los expedientes sobre imprentas de la oficina aragonesa ${ }^{50}$.

Las escribanías de Gobierno constituyeron pues el instrumento administrativo de que se sirvió el Consejo de Castilla durante los siglos XVIII y XIX para controlar la ingente producción escrita y la difusión y contagio de las ideas, que a fines del Setecientos resultaba ya imparable. Su producción documental, reflejada en el cuadro de clasificación de fondos del Archivo Histórico Nacional, revela unas oficinas especializadas y con unos procedimientos racionalizados y normalizados, que derivaron en la gestación del expediente administrativo contemporáneo.

A pesar de que queda aún un largo camino por recorrer y de que la descripción completa de esta documentación aportará, sin duda, nuevos datos y enfoques sobre el tema, la forma de trabajo y la metodología aplicada han permitido un profundo conocimiento sobre las impresiones controladas por la dinastía borbónica hasta 1834. Una metodología que defendemos y reivindicamos frente a quienes piensan que el trabajo del archivero consiste únicamente en la mera grabación de datos, en la descripción documento a documento y que consideran que cualquier reflexión más allá de ello corresponde únicamente a los investigadores. Con esto pretendemos cumplir con la que, a nuestro juicio, es la principal tarea de nuestra profesión en los archivos históricos, que no es otra que la de conservar los documentos y servir de guía a quienes pretenden acercarse al complejo mundo del pasado.

${ }^{49}$ MOLL, op. cit. (nota 4), p. 91.

${ }^{50}$ 1779, mayo, 16. AHN, Consejos, 37118, en ÁLVAREZ-COCA GONZÁLEZ, op.cit. (nota 5), p. 913. 